\title{
The Quantitative Effect of Blast Furnace Slag Composition and Temperature on the Kinetics of Potassium Evaporation
}

\author{
ANTON ANDERSSON, HESHAM AHMED, LENA SUNDQVIST ÖKVIST, \\ and BO BJÖRKMAN
}

\begin{abstract}
Increased in-plant recycling and lower quality raw material in terms of alkali content drive the alkali load in the blast furnace (BF) to higher levels. Excessive load of alkalis, primarily potassium, has several negative effects on the BF operation, which necessitates means to control the removal of potassium from the BF. One method to improve the removal is by increasing the potassium retention in the slag, which is controlled by the evaporation kinetics of potassium. Although several authors have studied factors affecting the evaporation rate, none of these studies have quantitatively investigated the effect of these parameters and attempted to relate these effects to slags from the industry. In the present work, a full-factorial design of experiments with three factors ( $\mathrm{B} 2$ basicity, $\mathrm{MgO}$ content, and temperature) was performed, studying the evaporation of potassium from synthetic BF slag. The results suggested that multiple linear regression is suitable to describe the evaporation kinetics of potassium within the boundaries of the design of experiments. However, extrapolating to industrial slags of different compositions and additional slag components is best performed utilizing the corrected optical basicity. The corrected optical basicity showed a linear relation to the evaporation kinetics of potassium, which was related to the correlation between diffusivity and corrected optical basicity.
\end{abstract}

https://doi.org/10.1007/s11663-020-01977-8

(C) The Author(s) 2020

\section{INTRODUCTION}

\section{A. Context}

INCREASED in-plant recycling and lower quality raw material in terms of alkali content drive the alkali load in the blast furnace (BF) to higher levels. Due to the detrimental effects of alkalis on the BF operation, these elements have to be controlled in order to achieve a smooth and efficient process.

ANTON ANDERSSON and BO BJÖRKMAN are with the Minerals and Metallurgical Engineering, Luleå University of Technology, 97187 Luleå, Sweden. Contact e-mail: anton.andersson@ltu.se HESHAM AHMED is with the Minerals and Metallurgical Engineering, Luleå University of Technology and also with the Central Metallurgical Research and Development Institute, P.O. Box 87, 11421 Helwan, Egypt. LENA SUNDQVIST ÖKVIST is with the Minerals and Metallurgical Engineering, Luleå University of Technology, Luleå and also with the Swerim AB, Box 812, 97125 Luleå, Sweden.

Manuscript submitted June 17, 2020; Accepted September 10, 2020.

Article published online October 9, 2020.
The alkalis of interest for the $\mathrm{BF}$ process are sodium and potassium, both of which enter the BF via the primary raw materials as well as recycled in-plant residues. From material balances, the introduction of alkalis in the top-charged materials is mainly attributed to the ferrous burden. ${ }^{[1,2]}$ However, Sukarovs et al. ${ }^{[3]}$ characterized a range of coke samples, finding that the alkali content varied between 0.11 and 0.30 wt pct, which suggests the possibility of significant contributions from the coke ash as well. Previously published material balances recognized the contribution of coke, presenting that the coke ash may account for as much as 22 to 56 pct of the total alkali load in the BF. ${ }^{[2,4]}$

The upper limit of allowed alkali load differs between different plants. Geerdes et al. ${ }^{[5]}$ reported that typical figures of upper limits vary between 1.5 and 5 $\mathrm{kg}$ of alkalis per ton hot metal (tHM). However, significantly higher alkali loads have been reported in commercial operation, e.g., publications with figures varying between 6.5 and $14 \mathrm{~kg}$ alkalis/tHM exist. ${ }^{[1,2,6-9]}$ In addition, $\mathrm{Lu}^{[10]}$ reported on declining qualities regarding the chemical composition of fine iron ore products and stated that the trend for continued downshift in iron ore quality is expected 
for the future. Similar observations have been reported, but specifically for the alkali content, in other publications as well. ${ }^{[2,6,11,12]}$ This trend suggests that alkali loads may increase in the future.

Another factor that drives the alkali load to higher levels is the increased recycling of in-plant residues. Both the domestic environmental legislation ${ }^{[13]}$ and efforts on improving raw material efficiency motivate increased recycling within the integrated steel plant. As an example, Wedholm ${ }^{[14]}$ reported that the amount of materials recycled via cold-bonded briquettes had increased fivefold going from 1993 to 2015. In terms of cold-bonded briquettes, the reported recycling rate employed in industrial scale is $100 \mathrm{~kg} / \mathrm{tHM}^{[15]}$ The reported $\mathrm{K}_{2} \mathrm{O}$ and $\mathrm{Na}_{2} \mathrm{O}$ contents of cold-bonded briquettes are 0.16 to $0.29 \mathrm{wt} \mathrm{pct}^{[15,16]}$ and $0.23 \mathrm{wt}$ pct, ${ }^{[16]}$ respectively. These figures translate to an increased alkali load of 0.39 to $0.52 \mathrm{~kg} / \mathrm{tHM}$, solely attributed to in-plant recycling. Furthermore, Togobitskaya et $a{ }^{\left[{ }^{[8]}\right.}$ reported, specifically, that periods with higher recycling rates of secondary raw materials had increased alkali loads due to variations in the potassium content of the sinter.

In order to understand the detrimental effects of alkalis on the BF operation, a brief introduction to the behavior of these elements in the BF is of interest. The majority of the alkali compounds are reduced to alkali metal and evaporates at the high temperatures above the tuyere level. ${ }^{[17]}$ As a direct effect, most of the alkalis ascend with the gas phase and are oxidized and condensed on the low-temperature burden descending counter-currently to the gas. ${ }^{[17]}$ Hatano et al. ${ }^{[17]}$ reported that less than 1 pct of the total outlet of alkalis from the BF occurred via the dust carried by the top gas. Therefore, the majority of the evaporated alkalis in the BF experience a cyclical behavior. ${ }^{[17]}$ Geerdes et al. ${ }^{[5]}$ reported that the circulating loads of alkalis in the BF could range between 3 and 10 times the inputs. On the other hand, analyses of materials in a chilled and dissected BF, with an inner volume of $128 \mathrm{~m}^{3}$, indicated that certain positions in the BF had 50 times higher alkali contents than the charged materials. ${ }^{[6]}$ However, the reported circulating load of $23 \mathrm{~kg}$ alkali/tHM from a dissected commercial $\mathrm{BF}^{[18]}$ indicates that, when considering positions other than the peak alkali analyses, the value of the circulating load resembles that presented by Geerdes et al..$^{[5]}$

High circulating loads of alkalis in the BF may cause scaffolding, ${ }^{[2,9,12,19-21]}$ which reduces the working volume and circumference of the shaft. Furthermore, scaffolding may result in irregular burden descent and, in extreme scenarios, hanging of the burden and slips. ${ }^{[2,9,22]}$

In addition to affecting the descent of the burden, alkalis directly affect the coke rate of the BF. The cyclical behavior of alkalis facilitates a reduction-evaporation-oxidation-condensation cycle, which increases the coke rate ${ }^{[8,20,21]}$ as the average potassium or sodium atom charged will experience this cycle several times before exiting the BF. Furthermore, the reduction and evaporation of alkalis in the lower part means that endothermic reactions occur, which in extreme scenarios may result in a chilled hearth at high alkali loads. ${ }^{[20]}$ Another pronounced effect is that alkalis catalyze the solution loss reaction, which translates to an increased coke rate and reduced hot coke strength. ${ }^{[6,8,9,21]}$

An additional reported effect of increased alkali loads is the swelling of the ferrous burden upon reduction ${ }^{[2,9,23]}$ and consequently weakening of the ferrous burden, which causes disintegration and reduced gas permeability. However, considering that Bahgat et al. ${ }^{[2]}$ found that $\mathrm{FeO}$ doped with $\mathrm{K}_{2} \mathrm{O}$ experienced less swelling and disintegration as compared to pure $\mathrm{FeO}$, the results on the matter of swelling are ambiguous. Furthermore, the results presented by Iljana et al. ${ }^{[23]}$ suggested that the effect of potassium on the swelling differs between BF operations with olivine-fluxed pellets and acid pellets.

Another detrimental effect of alkalis is the increasing refractory wear, ${ }^{[2,6,9,11,12,19-22,25-27]}$ which necessitates more frequent relining. More specifically, alkalis penetrate the carbon blocks and cause crack formation. ${ }^{[25,26]}$ In addition, Jiao et al. ${ }^{[27]}$ found that chlorides from the pulverized coal injection formed alkali chlorides, which were proposed as a cause for the major erosion observed in the carbon bricks of a blown-out commercial BF.

Due to the detrimental effects of high alkali loads in the BF, several strategies have been proposed and employed in order to mitigate accumulation in the BF. These strategies include (i) lowering the input of alkalis, ${ }^{[1,2,4,8,12,20-22]}$ (ii) maximizing the quality of sinter and coke, ${ }^{[20]}$ (iii) charging coarse dunite as an alkali removal agent, ${ }^{[28]}$ (iv) increasing the slag rate, ${ }^{[17,21]}$ and (v) altering the slag composition. ${ }^{[4,7-9,17,19-22,29]}$ In addition, less realistic suggestions for modern BF ironmaking have been proposed and operated, such as charging $\mathrm{CaCl}_{2}$ as an alkali cleaner ${ }^{[20-22]}$ and reducing in-plant recycling via the sinter. ${ }^{[20]}$

The effect of lowering the input of alkalis into the BF is significant, e.g., the thermodynamic model developed by Chen et al. ${ }^{[12]}$ suggested that increasing the potassium or sodium load by $1 \mathrm{~kg} / \mathrm{tHM}$ results in an increased circulating load by 27.7 and $15.5 \mathrm{~kg} / \mathrm{tHM}$, respectively. Furthermore, Jiao et al. ${ }^{[6]}$ calculated that increasing the potassium and sodium load by $1 \mathrm{~kg} / \mathrm{tHM}$ increases the coke rate by 13.99 and $6.25 \mathrm{~kg} / \mathrm{tHM}$, respectively.

Related to increasing the slag rate, Hatano et al. ${ }^{[17]}$ calculated that an optimum slag rate exists. By increasing the slag rate, higher removal capacities of potassium can be achieved, which lowers the alkali load in the BF and sequentially lowers the coke rate. ${ }^{[17]}$ However, increasing the slag rate requires an increased coke rate for melting the excess slag and, thus, a balance between the two effects can be reached. ${ }^{[17]}$

In terms of altering the slag composition, this strategy relates to the fact that the slag phase is the largest outlet of alkalis from the BF. Results from material balances presented in the literature reveal that the slag phase may account for 92 to 98.5 pct of the total alkali removal from the BF. ${ }^{[2,7,17,19]}$ However, cases of 20-78 pct removal via the slag exist. ${ }^{[1,20-22]}$ Considering these variations in the efficiency of utilizing the slag phase as the outlet of alkalis, the effect of altering the slag composition on the alkali capacity of the slag is of great interest to understand. Furthermore, Ivanov et al. ${ }^{[30]}$ 
discussed that maximizing alkali output via the slag is favorable over alkali loading in the BF dust. Therefore, the currently available scientific literature presenting alkali-related parameters for the BF slag was reviewed.

\section{B. Literature Review}

According to Geerdes et al., ${ }^{[5]}$ sodium is generally not a problem in the BF, except when charged in amounts larger than the potassium load. Therefore, the current paper will henceforth focus on potassium. In terms of the published scientific literature related to potassium in BF slag, the contents of the papers can be categorized as (i) effect of slag composition on potassium dissolution and evaporation in primary BF slags, ${ }^{[31,32]}$ (ii) factors governing alkali retention in the slag, ${ }^{[33-38]}$ (iii) simultaneous sulfur and potassium removal capacity, ${ }^{[39]}$ and (iv) kinetics of evaporation of potassium from $\mathrm{BF}$ slag. $[31,32,40-43]$

\section{Potassium dissolution and retention}

The first object of interest is to understand the dissolution of gaseous potassium in BF slag, which was reported by Amatatsu et al. ${ }^{[31]}$. On the other hand, the results of Ivanov et al., ${ }^{[32]}$ studying the evaporation of potassium from primary BF slags, describe the same phenomenon. While Amatatsu et al. ${ }^{[31]}$ observed that the potassium content in the slag approached equilibrium in an atmosphere of constant partial pressure of potassium, Ivanov et al. ${ }^{[32]}$ showed that primary BF slags reached a point where potassium does not continue to evaporate. Based on these results, Ivanov et al. ${ }^{[32]}$ concluded that the alkali-related purpose of the primary BF slag, containing iron oxide, is to dissolve the alkali vapor in the BF. Furthermore, based on these results, a great interest has been directed at factors determining how potassium can be retained in the BF slag and, thus, be removed from the alkali cycle.

One of the early studies on factors determining the alkali retention in BF slags was performed by Kärsrud. ${ }^{[33]}$ In the experiments, synthetic BF slags of different compositions were allowed to reach equilibrium with gaseous potassium of unknown partial pressure (i.e., not measured or estimated). ${ }^{[33]}$ The main findings can be summarized as $\mathrm{K}_{2} \mathrm{O}$ content in the slag decreases with increasing B3 basicity (Eq. [1]). Furthermore, at constant B3 basicity with an increasing amount of $\mathrm{MgO}$, the equilibrium $\mathrm{K}_{2} \mathrm{O}$ content in the slags increased.

$$
\mathrm{B} 3=\frac{\text { wt pet } \mathrm{CaO}+\text { wt pct } \mathrm{MgO}}{\text { wt pet } \mathrm{SiO}_{2}} .
$$

Bergman $^{[34]}$ utilized the results obtained by Kärsrud $^{[33]}$ and found that the optical basicity measurement, introduced to metallurgical slags by Duffy et al., ${ }^{[44]}$ provided a good description of the potassium capacity. The analysis of Kärsrud's ${ }^{[33]}$ results showed that the potassium capacity of the BF slags could be described by a linear function with a negative slope using the optical basicity as the variable of the function. ${ }^{[34]}$ Based on these results, authors of several papers ${ }^{[35-38]}$ have employed the optical basicity measurement to describe the potassium content of $\mathrm{BF}$ slags from different datasets with a similar outcome as Bergman. ${ }^{[34]}$ The concept of optical basicity is revisited later in the paper, and for now, results related to common parameters in the slag are reviewed.

Yang et $a l .{ }^{[35]}$ analyzed results of potassium contents in BF slags from both laboratory-scale experiments and industrial data. Based on the analysis, the potassium capacity of BF slag decreases with increasing temperature, increasing B2 basicity (Eq. [2]), and increasing $\mathrm{MgO}$ contents at constant $\mathrm{B} 2$ basicity. ${ }^{[35]}$ These results are in line with laboratory-scale experiments ${ }^{[38]}$ and industrial data ${ }^{[4,7-9,21,22,45-47]}$ presented in other publications. In addition to the aforementioned parameters, Xing et $a l .{ }^{[38]}$ found that increasing $\mathrm{Al}_{2} \mathrm{O}_{3}$ contents favored potassium retention in the $\mathrm{BF}$ slag while increasing $\mathrm{BaO}$ contents had a negative effect.

$$
\mathrm{B} 2=\frac{\text { wt pet } \mathrm{CaO}}{\text { wt pet } \mathrm{SiO}_{2}} \text {. }
$$

Although the results presented regarding the alkali capacity of BF slags are useful and provide good correlations between variations in potassium content and slag composition, the concept is misleading from the standpoint of fundamental understanding of the BF. As concluded by Fukutake et al., ${ }^{[40]}$ from a thermodynamic standpoint, the conditions in the lower part of the BF, characterized by high temperatures and reducing conditions, do not allow potassium to be present in the slag in significant amounts. Therefore, potassium retention in the slag is governed by the kinetics of potassium reduction and evaporation, not by the potassium content at thermodynamic equilibrium. ${ }^{[40]}$ Similar conclusions were presented based on the thermodynamic consideration presented by Rankin and See. ${ }^{[21]}$ Therefore, the alkali capacity of final BF slags is a misleading expression.

\section{Kinetics of evaporation of potassium from blast} furnace slag

Based on the abovementioned aspect of potassium content at equilibrium, Fukutake et al. ${ }^{[40]}$ were the first to study the evaporation of potassium from BF slag in the dripping zone of the BF. At this particular zone, the interfacial area between the slag and the gas phase is the largest, which suggests that this zone exerts the most significant contribution to the evaporation of potassium. ${ }^{[43]}$ In the experiments, Fukutake et al. ${ }^{[40]}$ showed that synthetic $\mathrm{BF}$ slags in the $\mathrm{K}_{2} \mathrm{O}-\mathrm{CaO}-\mathrm{Al}_{2} \mathrm{O}_{3}-\mathrm{SiO}_{2}$ system experience reduction and evaporation of $\mathrm{K}_{2} \mathrm{O}$ governed by the first-order reaction, Eq. [3].

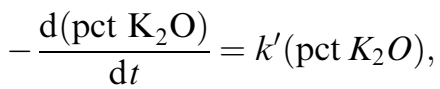

where $t$ is the time [s], pct $\mathrm{K}_{2} \mathrm{O}$ is the concentration of $\mathrm{K}_{2} \mathrm{O}$ in the slag [wt pct], and $k^{\prime}$ is the apparent rate constant $\left[\mathrm{s}^{-1}\right]$. 
The first-order reaction kinetics has later been confirmed and further studied, as reported in several scientific publications. ${ }^{[31,32,41-43]}$ These reports include the changes in the apparent rate constant with changes in basicity, $[31,32,40,42,43]$ additions of amphoteric components, ${ }^{[31,32,41]}$ changes in temperature, $[31,32,40,42,43]$ different gas parameters, ${ }^{[40,43]}$ shift in wetting behavior, ${ }^{[42]}$ and alterations of crucible material. ${ }^{[43]}$ A summary of the systems and experimental conditions of previously published research is presented in Table I. The results from the abovementioned studies are summarized in the text below, starting with the effect of gas parameters, as this highlights the mechanism of potassium evaporation from the slag.

Two different parameters with regard to the gas have been studied, namely, gas velocity over the surface of the slag and reducing potential of the gas. ${ }^{[40,43]}$ The influence of the gas velocity on the apparent rate constant was found to be negligible, ${ }^{[40,43]}$ the implications of which are further discussed in Section III-E. On the other hand, the reducing potential of the gas was found to affect the apparent rate constant, although the results of Fukutake et al. ${ }^{[40]}$ and Forsberg ${ }^{[43]}$ were partly inconsistent. Forsberg ${ }^{[43]}$ observed a linear increase in the apparent rate constant with increasing partial pressures of carbon monoxide (ranging from 0 to 1 atm) in the gas phase, while Fukutake et al. ${ }^{[40]}$ reported that the effect of the reducing potential is insignificant at low partial pressures of oxygen. As an example, the apparent rate constant in nitrogen gas atmosphere was similar to carbon monoxide atmosphere, whereas air atmosphere had significantly lower evaporation rates. ${ }^{[40]}$

Forsberg $^{[43]}$ determined that, although the apparent rate constant was affected by the reducing power of the gas, the rate of evaporation was considerable also in inert atmosphere. Based on these results, Forsberg ${ }^{[43]}$ concluded that the evaporation of potassium from $\mathrm{BF}$ slags could be described by two mechanisms: dissociative evaporation, according to Eq. [4], and reduction, according to Eq. [5]. The former is present in inert atmosphere, and the latter is contributing in reducing atmospheres. Based on these findings, the results of Fukutake et al. ${ }^{[40]}$ suggest that the contribution of the dissociative evaporation to the overall reaction was dominating in their experiments.

$$
2\left[\mathrm{~K}^{+}\right]_{\text {slag }}+\left[\mathrm{O}^{2-}\right]_{\text {slag }} \rightarrow 2 \mathrm{~K}(\mathrm{~g})+\frac{1}{2} \mathrm{O}_{2}(\mathrm{~g})
$$

$$
2\left[\mathrm{~K}^{+}\right]_{\text {slag }}+\left[\mathrm{O}^{2-}\right]_{\text {slag }}+\mathrm{CO}(\mathrm{g}) \rightarrow 2 \mathrm{~K}(g)+\mathrm{CO}_{2}(\mathrm{~g}) .
$$

Considering that carbon monoxide may contribute to the evaporation of potassium according to Eq. [5], Forsberg $^{[43]}$ investigated the possibility of the reaction between the slag and graphite crucible. By studying identical experimental setups, using both graphite and boron nitride crucibles, Forsberg ${ }^{[43]}$ concluded that the evaporation of potassium is unaffected by the contact between the slag and a solid reducing agent.
In terms of studying the effect of altering the chemical composition of the slag, the most studied parameter is variations in basicity. The three different slag compositions studied by Fukutake et al. ${ }^{[40]}$ had B2 basicities ranging between 0.52 and 1.33 . The results of the experiments suggested that the apparent rate constant of potassium evaporation increased consistently with increasing B2 basicity. ${ }^{[40]}$ This trend was later confirmed in experiments reported in several publications. ${ }^{[31,32,41,43]}$ However, Shimoo et al. ${ }^{[42]}$ found results that indicated a change in the wetting behavior of the slag on the crucible wall upon changing the B2 basicity. As a consequence, the slag experienced a larger surface area exposed to the gaseous phase at lower basicities as compared to higher basicities and, therefore, inconsistent results in evaporation rate were noted. Nonetheless, at a constant wetting behavior, increasing basicities were found to consistently increase the rate of evaporation of potassium. ${ }^{[42]}$

In addition to altering the composition by changing the B2 basicity, Amatatsu et al. ${ }^{[31]}$ studied the effect of varying the $\mathrm{MgO}$ content of the slag while keeping the B3 basicity constant. The results showed that replacing $\mathrm{CaO}$ with $\mathrm{MgO}$ resulted in lower evaporation rates of potassium. ${ }^{[31]}$ These results could not be confirmed by Forsberg, ${ }^{[43]}$ who presented similar apparent rate constants at constant $\mathrm{B} 3$ basicity with varying $\mathrm{MgO}$ contents. Also, Ivanov et al. ${ }^{[32]}$ reported inconsistent effects on the evaporation kinetics of potassium upon changes in $\mathrm{MgO}$ content at constant $\mathrm{B} 2$ basicity. In their results, variations between 7.7 and 9.4 wt pet $\mathrm{MgO}$ had less effect, while higher $\mathrm{MgO}$ contents significantly increased the apparent rate constant. ${ }^{[32]}$ Thus, the available literature on the effect of $\mathrm{MgO}$ content shows ambiguous results.

The influence of other components has been studied by varying the $\mathrm{Al}_{2} \mathrm{O}_{3},{ }^{[31,32,41]} \mathrm{TiO}_{2},{ }^{[31,41]}$ and $\mathrm{FeO}^{[31]}$ content of the slag. Additions of amphoteric components, i.e., $\mathrm{Al}_{2} \mathrm{O}_{3}$ and/or $\mathrm{TiO}_{2}$, were performed at $\mathrm{B} 2$ basicities of $1.20^{[31,41]}$ and $1.07 .^{[32]}$ The results were consistent in showing that higher contents of these amphoteric components decreased the evaporation rate of potassium from the slag. ${ }^{[31,32,41]}$ Furthermore, Amatatsu et al. ${ }^{[31]}$ showed that adding $\mathrm{FeO}$ at a B2 basicity of 0.8 significantly increased the rate of evaporation of potassium.

Apart from the chemical composition of the slag, the most influential parameter on the apparent rate constant is the temperature. With regard to this parameter, all experimental results are consistent in showing that increasing temperatures are associated with an increased reaction rate. ${ }^{[31,32,40-43]}$

Based on the above, the evaporation of potassium from BF slag is a well-studied area with mostly consistent results. However, there are specific characteristics of the existing data that need to be addressed, e.g., confirming the effect of changes in $\mathrm{MgO}$ content and determining evaporation data for slags with high $\mathrm{MgO}$ contents in ranges relevant for BFs operating on olivine-fluxed pellets. Furthermore, experiments utilizing synthetic slags of different compositional ranges have never been followed up using slags of similar 
Table I. Summary of Studies on the Evaporation Kinetics of Potassium from BF Slag

\begin{tabular}{|c|c|c|c|c|c|c|c|c|}
\hline Study & Slag & $\underset{\mathrm{N})}{\mathrm{MgO}(\mathrm{Y} /}$ & $\begin{array}{c}\mathrm{TiO}_{2}(\mathrm{Y} / \\
\mathrm{N})\end{array}$ & $\begin{array}{c}\mathrm{FeO}(\mathrm{Y} / \\
\mathrm{N})\end{array}$ & B2 & $\begin{array}{l}\mathrm{MgO}[\mathrm{Wt} \\
\mathrm{Pct}]\end{array}$ & $\begin{array}{c}\text { Temperature } \\
{[\mathrm{K}]}\end{array}$ & Crucible \\
\hline $\begin{array}{l}\text { Fukutake } \\
\text { et al. } .^{[40]}\end{array}$ & synthetic & $\mathrm{N}$ & $\mathrm{N}$ & $\mathrm{N}$ & 0.52 to 1.33 & 0 & 1573 to 1813 & $\mathrm{C}$ and $\mathrm{MgO}$ \\
\hline $\begin{array}{l}\text { Friedrichs } \\
\text { et al. } .^{41]}\end{array}$ & synthetic & $\mathrm{N}$ & $\mathrm{Y}$ & $\mathrm{N}$ & 0.80 to 1.20 & 0 & 1573 to 1773 & $\mathrm{C}$ \\
\hline Shimoo et al..$^{[42]}$ & synthetic & $\mathrm{N}$ & $\mathrm{N}$ & $\mathrm{N}$ & 0.47 to 1.30 & 0 & 1723 to 1923 & $\mathrm{C}$ \\
\hline $\begin{array}{l}\text { Amatatsu } \\
\text { et al. }\end{array}$ & synthetic & $\mathrm{Y}$ & $\mathrm{Y}$ & $\mathrm{Y}$ & 0.80 to 1.20 & 0 to 8.86 & 1573 to 1773 & $\mathrm{C}$ and $\mathrm{Mo}$ \\
\hline Forsberg $^{[43]}$ & synthetic & $\mathrm{Y}$ & $\mathrm{N}$ & $\mathrm{N}$ & 0.77 to 1.29 & 5 to 12 & 1723 to 1823 & $\mathrm{C}$ and $\mathrm{BN}$ \\
\hline Ivanov et al..$^{[32] *}$ & synthetic & $\mathrm{Y}$ & $\mathrm{N}$ & $\mathrm{N}$ & 0.85 to 1.05 & 7.0 & 1673 to 1773 & $\mathrm{C}$ \\
\hline Ivanov et al..$^{[32]}$ & industrial & $\mathrm{Y}$ & $\mathrm{Y}$ & $\mathrm{Y}$ & 1.15 to 1.19 & 7.7 to 10.2 & 1773 & $\mathrm{C}$ \\
\hline
\end{tabular}

All studies utilized slags with $\mathrm{K}_{2} \mathrm{O}, \mathrm{CaO}, \mathrm{Al}_{2} \mathrm{O}_{3}$, and $\mathrm{SiO}_{2}$ as components, and the inclusion of additional components are marked as Yes (Y) or No $(\mathrm{N})$ in the table. $\mathrm{BN}$ denotes boron nitride.

*Experiments reported for primary slags were disregarded in this table as this composition does not represent the dripping zone.

composition from industrial operation. Finally, no attempts to quantitatively relate the apparent rate constant to the composition of the slag in more extensive systems than the studied synthetic BF slag have been performed. Based on the identified characteristics of the existing data, the present study addresses these aspects by studying the evaporation rate of potassium in a set of experiments designed using a two-level full-factorial design of experiments.

\section{EXPERIMENTAL}

\section{A. Slag Compositions and Synthesis}

The impact of BF slag composition and temperature on the kinetics of potassium evaporation was quantitatively estimated using synthetic BF slags. A two-level full-factorial design of experiments with the three variables $\mathrm{B} 2$ basicity, wt pct $\mathrm{MgO}$, and temperature was employed. By utilizing a two-level full-factorial design of experiments, each variable can be evaluated independently. In addition, two-factor interaction effects between parameters can be determined.

The compositional ranges and temperature range are presented in the experimental matrix shown in Figure 1. The basicity was chosen to be varied between 0.8 and 1.1 to cover a wide range of operational conditions. Furthermore, the range of wt pct $\mathrm{MgO}$ was designed to represent the high $\mathrm{MgO}$ contents of the $\mathrm{BFs}$ operating on olivine-fluxed pellets. The temperature was varied to see the effect of changed heat levels, and the three center points were utilized to evaluate the reproducibility of the experiments.

The slag compositions required for the tests included in the experimental design were synthesized prior to the actual potassium evaporation experiments. Table II presents the five different slag compositions utilized, and each slag represents a sphere along the compositional plane, composed of the $\mathrm{B} 2$ and $\mathrm{MgO}$ axes, in Figure 1.

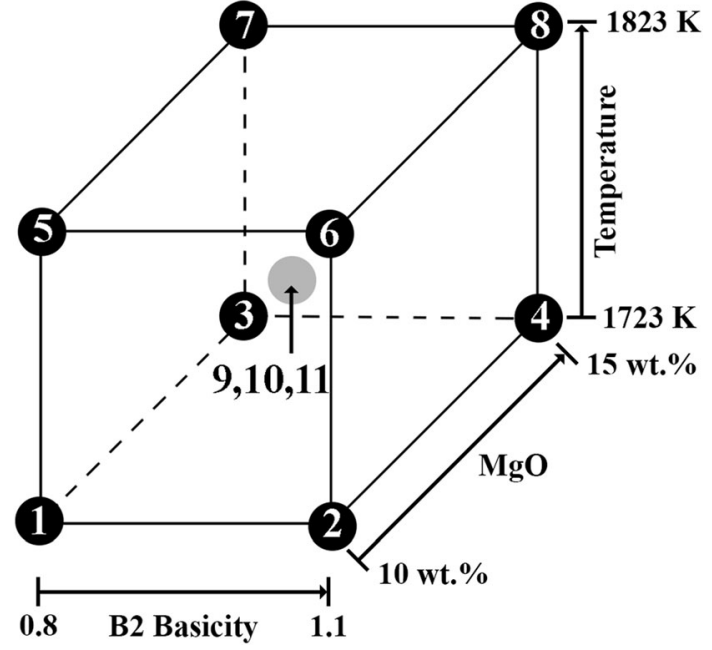

Fig. 1-Experimental matrix for the design of experiments.

The chemicals utilized for the synthesis were $\mathrm{CaCO}_{3}$ of 99.5 pet grade produced by ThermoFisher, $\mathrm{MgO}$ of 99.0 pct grade from Honeywell, $\mathrm{SiO}_{2}$ of 99.5 pct grade from ThermoFisher, and $\mathrm{Al}_{2} \mathrm{O}_{3}$ of 99.9 pct grade from Alfa Aesar. The slags were melted in graphite crucibles in an Entech ECF 10/18 chamber furnace at a temperature exceeding the liquidus temperature. The liquidus temperature was calculated for each slag utilizing the Equilib module of FactSage 7.1 with the FactPS and FToxid databases. The synthesis was performed in ambient atmosphere as the BF slag system is stable.

After the synthesis, the slags had some larger grains formed during the cooling; therefore, each slag was crushed and finely ground individually. Representative samples of the ground slags were used in the subsequent experiments. 


\section{B. Evaporation experiments}

The experimental setup utilized for the evaporation experiments is presented in Figure 2. A Ruhstrat resistance heating furnace was controlled against an $\mathrm{S}$-type $\mathrm{Pt} / \mathrm{Pt} 10 \mathrm{Rh}$ thermocouple. In order to measure the temperature as close to the melted slag as possible, the thermocouple was enclosed by a graphite sheath and placed in the slag. $\mathrm{N}_{2}$ was introduced into the crucible and at the bottom of the furnace in volumes of $2 \mathrm{~L} / \mathrm{min}$ ambient temperature and pressure (ATP) and $8 \mathrm{~L} / \mathrm{min}$ ATP, respectively. The bottom gas was utilized to protect the graphite from reacting with oxygen.

Prior to each experiment, $200.00 \mathrm{~g}$ of the synthesized BF slag was mixed with $9.08 \mathrm{~g} \mathrm{~K}_{2} \mathrm{CO}_{3}$ of reported 100 pct purity, produced by $\mathrm{BDH}$ Prolabo. The $\mathrm{K}_{2} \mathrm{CO}_{3}$ addition corresponds to a total $\mathrm{K}_{2} \mathrm{O}$ content of $3.0 \mathrm{wt}$ pct in the synthetic BF slag, which allowed the evaporation to occur in a range of potassium contents relevant for the process. A total of 10.09 to $10.15 \mathrm{~g}$ of solid cylinders made of graphite was added to the mixture. The graphite cylinders roughly represented a monolayer on the slag surface after melting. These cylinders,

Table II. Slag Compositions Synthesized for the Experiments

\begin{tabular}{lccccc}
\hline Slag & $\mathrm{B} 2$ & $\mathrm{CaO}$ & $\mathrm{SiO}_{2}$ & $\mathrm{Al}_{2} \mathrm{O}_{3}$ & $\mathrm{MgO}$ \\
\hline No. 1 & 0.80 & 34.7 & 43.3 & 12.0 & 10.0 \\
No. 2 & 1.10 & 40.9 & 37.1 & 12.0 & 10.0 \\
No. 3 & 0.80 & 32.4 & 40.6 & 12.0 & 15.0 \\
No. 4 & 1.10 & 38.2 & 34.8 & 12.0 & 15.0 \\
No. 5 & 0.95 & 36.8 & 38.7 & 12.0 & 12.5 \\
\hline
\end{tabular}

The values are reported in wt pct, except for B2, which is unitless. Note that the Slag No. is different from the experiment No. of Fig. 1.

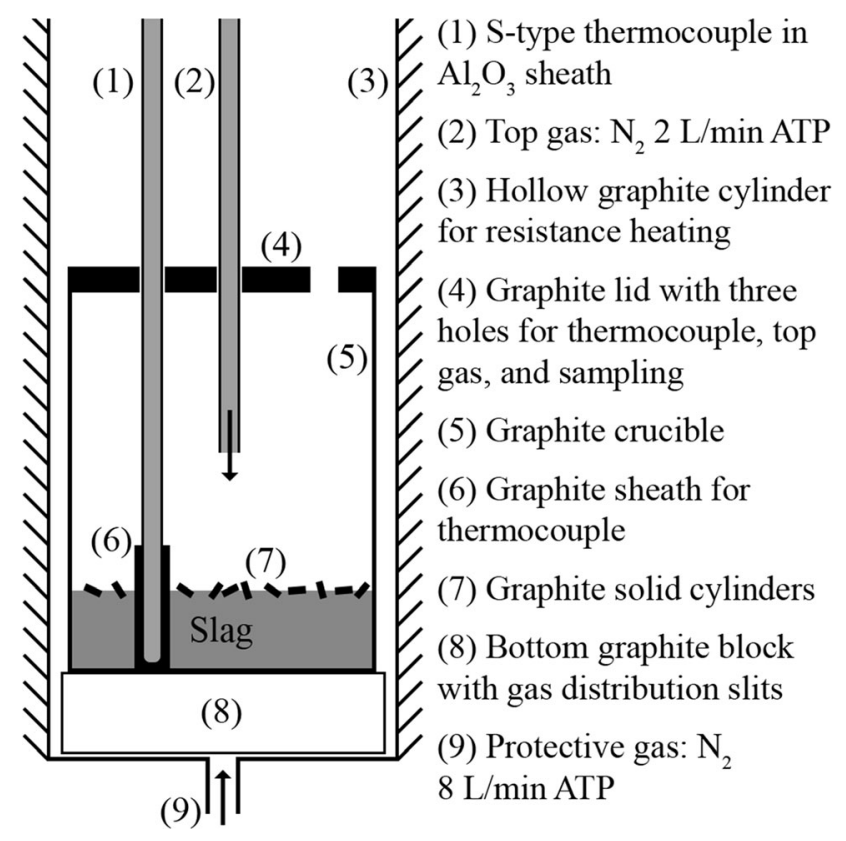

Fig. 2-Experimental setup in the evaporation experiments. together with the graphite crucible and thermocouple sheath, were aimed to represent the coke in the coke/slag system. Actual coke pieces were omitted to avoid coke ash from altering the slag composition.

In the experiments, a heating rate of $10 \mathrm{~K} / \mathrm{min}$ was utilized, and the first sampling was performed when the experimental temperature of 1723,1773 , or $1823 \mathrm{~K}$ was reached. The first sampling point was labeled $t=0$, which represents time of zero minutes after reaching the experimental temperature. Subsequent sampling was performed after 5, 10, 20, 40, 80, and $120 \mathrm{~min}$. Each sample was taken by freezing of slag on a copper rod.

Digestion of the samples was performed in aqua regia at $373 \mathrm{~K}$. The solutions were analyzed using inductively coupled plasma optical emission spectroscopy (ICP-OES) in a ThermoScientific iCAP 7200 instrument.

\section{Experiments on blast furnace slags from industrial practice}

The kinetics of potassium evaporation from four BF slags sampled from two European BFs were studied at a temperature of $1723 \mathrm{~K}$ using the same experimental setup as previously presented. Figure 3 presents the relation of the $\mathrm{MgO}$ content and $\mathrm{B} 2$ basicity to the experimental matrix of Figure 1. The chemical compositions of the slags are presented in Table III. Prior to the experiments, $\mathrm{K}_{2} \mathrm{CO}_{3}$ was added to achieve a potassium content of $3 \mathrm{wt}$ pct. The amount of $\mathrm{K}_{2} \mathrm{CO}_{3}$ added to reach 3.0 wt pet $\mathrm{K}_{2} \mathrm{O}$ was based on the original potassium content of the slags, as seen in Table III.

\section{RESULTS AND DISCUSSION}

\section{A. Evaluation of Experimental Setup}

The idea of the experimental setup presented in the present paper was to allow sampling from the same melt throughout each unique experimental condition. This experimental procedure deviates from previously utilized methods. In the present experiments, samples were withdrawn from the slag melt after predetermined times. In comparison, previously reported experiments were performed using multiple crucibles containing melts of the same composition, which were withdrawn and

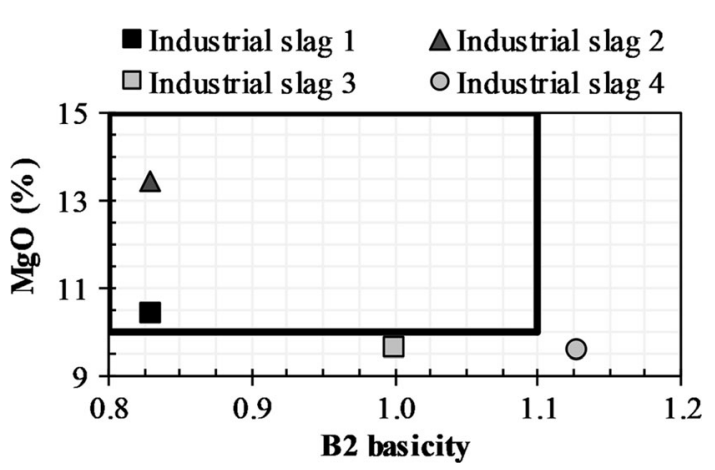

Fig. 3- $\mathrm{MgO}$ content and $\mathrm{B} 2$ basicity of the industrial slag samples in relation to the composition of the synthetic slags, as marked by the thick black outline. 
quenched after different times spent at the desired temperature. Therefore, the feasibility of the employed experimental setup was evaluated by including an experiment run in triplicate, i.e., experiment number 9 , 10, and 11 in Figure 1. The results of the triplicate experiments, illustrated in Figure 4, show good repeatability.

The results of the evaporation experiments were evaluated using the first-order kinetics according to Eq. [3]. The equation was integrated with the initial $\mathrm{K}_{2} \mathrm{O}$ content at a time of $t=0 \mathrm{~s}$, giving the expression presented in Eq. [6].

$$
-\ln \left[\left(\mathrm{K}_{2} \mathrm{O}_{t}\right) /\left(\mathrm{K}_{2} \mathrm{O}_{t=0}\right)\right]=k^{\prime} t,
$$

where $\mathrm{K}_{2} \mathrm{O}_{\mathrm{t}}$ is the $\mathrm{K}_{2} \mathrm{O}$ content [wt pct] at a given time $t$ [s], $\mathrm{K}_{2} \mathrm{O}_{t=0}$ is the $\mathrm{K}_{2} \mathrm{O}$ content [wt pct] at a time of $t=0 \mathrm{~s}, k^{\prime}$ is the apparent rate constant $\left[\mathrm{s}^{-1}\right]$, and $t$ is the time [s].

By plotting the experimental results and adopting a least-square fit of a first-degree polynomial that passes through the origin in the Euclidean plane, the apparent rate constant could be determined as the slope of the linear function. Figure 5 illustrates the results of experiment No. 9 plotted according to the abovementioned approach. To extract the data of the least-square fit, the Regression tool of the add-in Analysis ToolPak of Microsoft Excel was utilized. The slope of the linear fit

Table III. Chemical Composition of Industrial Slags, Marked as 1 to 4, Given in Wt Pet

\begin{tabular}{lrrrr}
\hline Component & 1 & 2 & \multicolumn{1}{c}{3} & \multicolumn{1}{c}{4} \\
\hline $\mathrm{CaO}$ & 31.16 & 31.87 & 38.47 & 40.10 \\
$\mathrm{MgO}$ & 10.42 & 13.45 & 9.61 & 9.59 \\
$\mathrm{Al}_{2} \mathrm{O}_{3}$ & 11.92 & 11.98 & 9.24 & 11.31 \\
$\mathrm{SiO}_{2}$ & 37.53 & 38.45 & 38.42 & 35.56 \\
$\mathrm{~K}_{2} \mathrm{O}$ & 1.89 & 1.04 & 1.26 & 0.57 \\
$\mathrm{Na}_{2} \mathrm{O}$ & 0.49 & 0.61 & 0.54 & 0.36 \\
$\mathrm{~S}$ & 0.65 & 1.05 & 1.09 & 1.52 \\
$\mathrm{TiO}_{2}$ & 0.50 & 0.34 & 0.34 & 0.25 \\
$\mathrm{MnO}$ & 1.91 & 0.87 & 0.73 & 0.38 \\
$\mathrm{Fe}$ & 3.52 & 0.23 & 0.25 & 0.29 \\
$\mathrm{BaO}$ & 0.00 & 0.10 & 0.06 & 0.08 \\
$\mathrm{P}_{2} \mathrm{O}_{5}$ & 0.02 & 0.00 & 0.00 & 0.00 \\
\hline
\end{tabular}

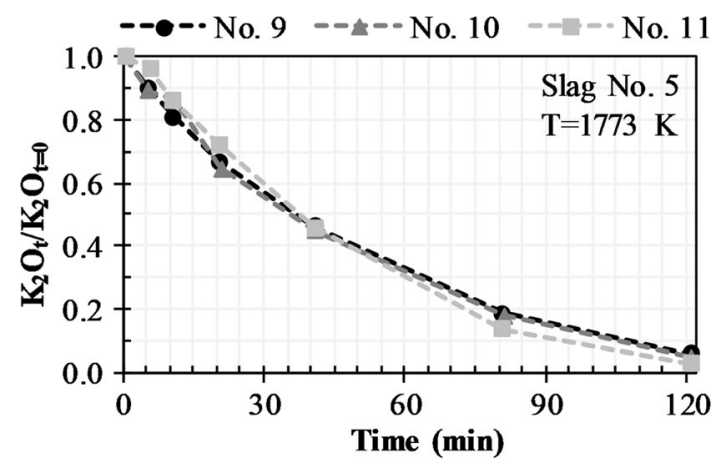

Fig. 4-Evaporation curves of the experiment run in triplicate. shows that the apparent rate constant under the employed conditions was $3.73 \times 10^{-4} \mathrm{~s}^{-1}$, determined with a coefficient of determination $\left(R^{2}\right)$ of 0.996 . The coefficient of determination is similar to previously reported values. ${ }^{[43]}$ Based on the above, the experimental setup was considered to produce reliable and reproducible results.

\section{B. Multiple Linear Regression Analysis}

The results of experiment No. 9, as well as the remaining experiments, evaluated using the aforementioned approach, are presented in Table IV. The data presented in Table IV were modeled by multiple linear regression, Eq. [7], using the statistical software MODDE Pro, developed by Umetrics.

$$
\begin{aligned}
k^{\prime}= & C_{0}+C_{1} \mathrm{~B} 2+C_{2}(\mathrm{MgO})+C_{3} T+C_{4} \mathrm{~B} 2(\mathrm{MgO}) \\
& +C_{5} \mathrm{~B} 2 \mathrm{~T}+C_{6}(\mathrm{MgO}) T+\varepsilon,
\end{aligned}
$$

where $k^{\prime}$ is the apparent rate constant $\left[\mathrm{s}^{-1}\right], C_{0}$ a constant, $C_{1}$ through $C_{6}$ the model parameters, B2 the basicity, $\mathrm{MgO}$ the $\mathrm{MgO}$ content [wt pct], $T$ the temperature $[\mathrm{K}]$, and $\varepsilon$ the residual response variable not explained by the model.

Fitting the data to Eq. [7], using least-square fit, resulted in a poor model. Although the coefficient of determination and experimental reproducibility were satisfactory, the goodness of prediction $\left(Q^{2}\right)$ was 0.22 , which is unacceptable. The coefficient of determination and goodness of prediction were calculated as per usual. ${ }^{[4]}$ The reproducibility was calculated according to Eq. [8].

$$
\text { Reproducibility }=1-\mathrm{MS}_{\mathrm{PE}} / \mathrm{MS}_{\mathrm{Tot}} \text {, }
$$

where $\mathrm{MS}_{\mathrm{PE}}$ is the mean square of the pure error, and $\mathrm{MS}_{\text {tot }}$ is the total mean square.

The main features of the model that showed potential for improvement were skewness of the distribution of the response parameter $k^{\prime}$ and removal of statistically insignificant parameters. By transforming the $k^{\prime}$ values by log-transformation, i.e., calculating the logarithm of all $k^{\prime}$ values using the base ten, the skewness was minimized. The insignificant parameters of the least importance to the model were removed one by one. These insignificant parameters were the model parameters $C_{4}$ and $C_{6}$. The final model had a coefficient of determination, goodness of prediction, model validity

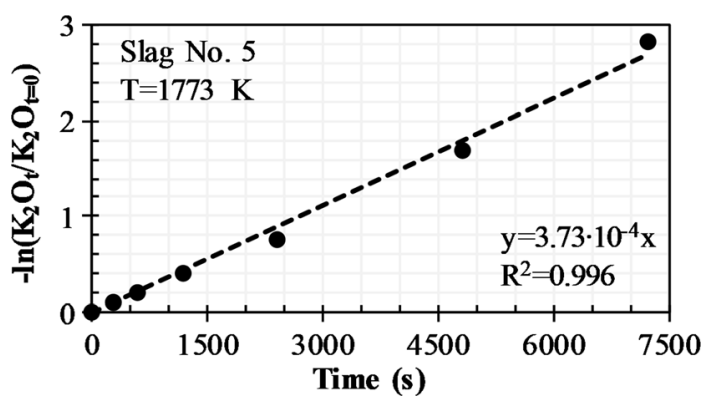

Fig. 5-Experiment No. 9 evaluated using the first-order kinetics. 
Table IV. Experimental Data for the Experiments

\begin{tabular}{|c|c|c|c|c|c|}
\hline No. & B2 & $\mathrm{MgO}$ & $T$ & $k^{\prime} \times 10^{4}$ & $R^{2}$ \\
\hline 1 & 0.80 & 10.0 & 1723 & 1.53 & 1.00 \\
\hline 2 & 1.10 & 10.0 & 1723 & 3.36 & 0.99 \\
\hline 3 & 0.80 & 15.0 & 1723 & 1.59 & 0.97 \\
\hline 4 & 1.10 & 15.0 & 1723 & 4.61 & 1.00 \\
\hline 5 & 0.80 & 10.0 & 1823 & 3.24 & 0.97 \\
\hline 6 & 1.10 & 10.0 & 1823 & 8.15 & 0.98 \\
\hline 7 & 0.80 & 15.0 & 1823 & 5.46 & 0.99 \\
\hline 8 & 1.10 & 15.0 & 1823 & 8.86 & 1.00 \\
\hline 9 & 0.95 & 12.5 & 1773 & 3.73 & 1.00 \\
\hline 10 & 0.95 & 12.5 & 1773 & 3.96 & 0.99 \\
\hline 11 & 0.95 & 12.5 & 1773 & 4.65 & 0.98 \\
\hline
\end{tabular}

$\mathrm{MgO}$ given in wt pet, temperature $(T)$ in Kelvin, and $k^{\prime}$ in $\mathrm{s}^{-1}$.

$\square \mathrm{B} 2 \square$ wt.\% MgO $\square$ Temp. $\square \mathrm{B} 2 \cdot \mathrm{Temperature}$

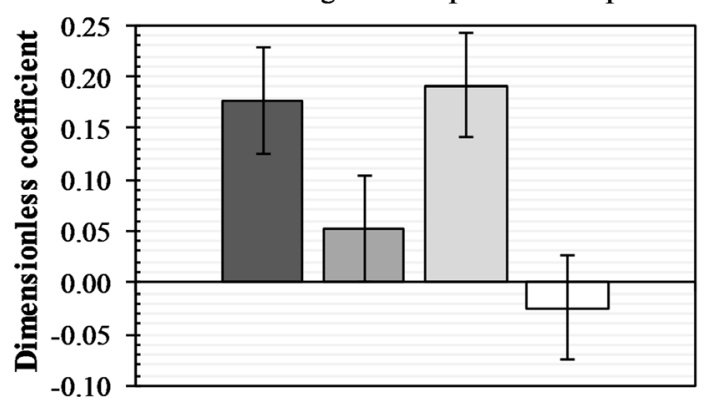

Fig. 6-Scaled and centered coefficients describing the model parameters. The superimposed error bars were determined on the 95 pct confidence interval.

(calculated using Eq. [9]), and reproducibility of 0.96, $0.84,0.78$, and 0.96 , respectively. These values indicate that the model described the dataset satisfactorily.

$$
\text { Model validity }=1+0.57647 \log p_{\mathrm{LoF}} \text {, }
$$

where $p_{\mathrm{LoF}}$ is the $p$ value for the lack-of-fit test, and the constant 0.57647 is chosen such that $p_{\mathrm{LoF}} \geq 0.05$ results in a model validity $\geq 0.25$. According to Eriksson et al., ${ }^{[48]}$ a model validity lower than 0.25 represents a model with a significant lack-of-fit.

The scaled and centered model parameters of the final model are presented in Figure 6. The centering refers to that the center point in Figure 1 attains the coordinate $\{0,0,0\}$ for the parameters $\{\mathrm{B} 2, \mathrm{~T}, \mathrm{MgO}\}$. Furthermore, the scaling refers to that the upper and lower endpoints of $\{\mathrm{B} 2, \mathrm{~T}, \mathrm{MgO}\}$ were set to $\{1,1,1\}$ and $\{-1,-1,-1\}$, respectively. This approach allows the comparison of the scaled effects within the experimental matrix. The results presented in Figure 6 shows that the relative effect of changing the temperature within the range of 1723 and $1823 \mathrm{~K}$ on the apparent rate constant is comparable to a change in $\mathrm{B} 2$ basicity within the range of 0.8 and 1.1 .

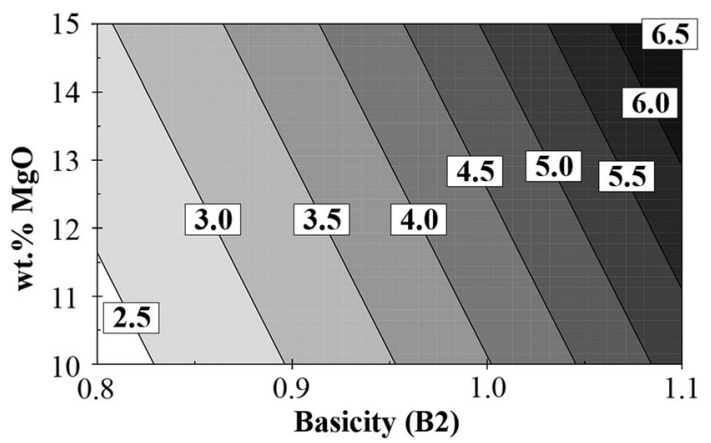

Fig. 7-Contour plot showing $10^{4} \times k^{\prime}$ (in white boxes assigned to black boundary lines) as a function of $\mathrm{B} 2$ basicity and wt pet $\mathrm{MgO}$ at $1773 \mathrm{~K}$.

Based on the literature review presented in Section I-B, previously reported experiments suggested that the effect of $\mathrm{MgO}$ on the apparent rate constant was ambiguous. Furthermore, data within compositional ranges of slags from BFs operating on olivine-fluxed pellets were lacking. According to the present evaluation, increasing $\mathrm{MgO}$ contents within the tested experimental matrix has a statistically significant effect on the apparent rate constant within the 95 pct confidence interval, Figure 6. Furthermore, in the compositional range of BF slags from BFs operating on olivine pellets, the scaled effect of increasing $\mathrm{MgO}$ contents on the apparent rate constant is 29 and 27 pct of the corresponding change in $\mathrm{B} 2$ and temperature, respectively.

The rightmost column in Figure 6 suggests that temperature and $\mathrm{B} 2$ basicity has a negative interaction effect on the apparent rate constant. However, as the error bar crosses the center point, the effect is not statistically significant within the 95 pct confidence interval. Nonetheless, the interaction parameter was kept in the model as the residuals attained a curvature form if the parameter was removed. On the other hand, keeping the parameter resulted in a linear form of the residuals, which is desired. The final form of Eq. [7], 

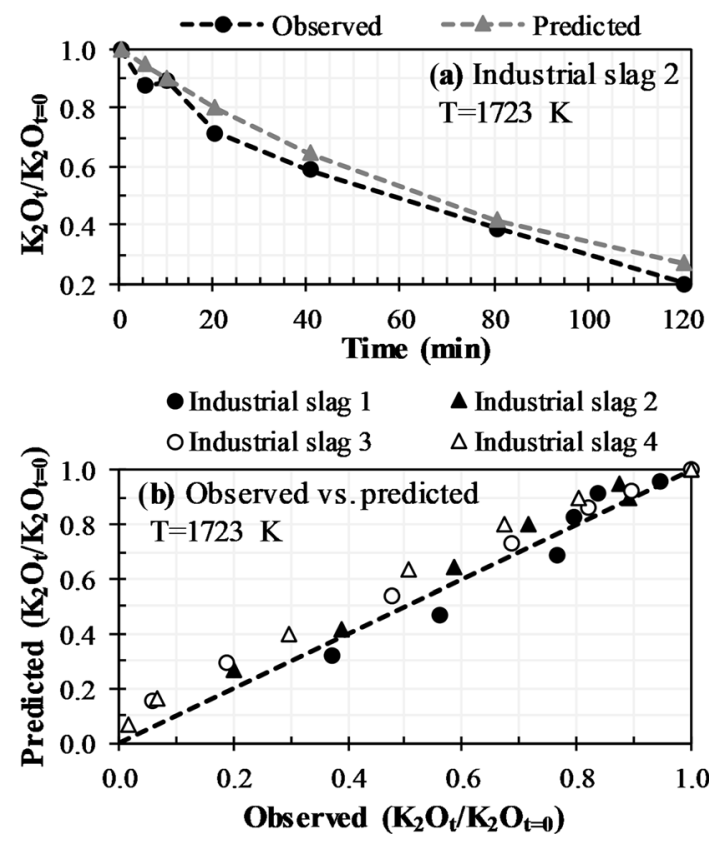

Fig. 8 - (a) Observed and predicted evaporation curves for industrial slag 2. (b) Observed vs predicted values for all industrial slags (the broken line is $1: 1$ )

with the logarithm of $k^{\prime}$, the inclusion of the aforementioned interaction parameter, and using zero values of $\mathrm{C}_{4}$ and $\mathrm{C}_{6}$, is presented in Eq. [10].

$$
\begin{aligned}
\log k^{\prime}= & -17.0+6.89 B 2+0.0209 M g O+0.00688 T \\
& -0.00322 B 2 T .
\end{aligned}
$$

Equation [10] can be used to quantitatively describe changes in the apparent rate constant with changes in the temperature and composition of the slag. As an example, Figure 7 illustrates a contour plot where the ranges of the apparent rate constant correspond to the greyscale fields within the Euclidian plane.

One of the identified questions raised based on the literature review was if the evaporation data determined for synthetic slags could be translated to evaporation data for industrial slags of similar composition. Therefore, the present model was used to predict the evaporation rate of potassium from industrial slags of comparable compositions as the synthetic slag, Figure 3, and Table III.

\section{Industrial Slag Samples}

The composition of the industrial slags, Table III, were utilized to calculate the apparent rate constants using Eq. [10] for a temperature of $1723 \mathrm{~K}$. Based on these modeled values, the predicted evaporation curves of potassium were compared to the observed curves from the laboratory-scale experiments. The best fit between observed and predicted was seen for the second industrial slag, illustrated in Figure 8(a). Considering all predicted and observed measurement points, the model consistently underestimated the evaporation rate of potassium in all slags, except three points for the first industrial slag, Figure 8(b).

Regarding the abovementioned observation, the model appears to confidently explain the dataset using synthetic slags while consistently providing a slight deviation in the prediction of the evaporation from industrial slags. The experiments performed on synthetic slags were done in the five-component system $\mathrm{K} 2 \mathrm{O}-\mathrm{CaO}-\mathrm{MgO}-\mathrm{Al}_{2} \mathrm{O}_{3}-\mathrm{SiO}_{2}$ with constant $\mathrm{Al}_{2} \mathrm{O}_{3}$ content. Since the repeatability of the experimental setup was good, Figure 4, the deviation from the model experienced by the industrial slags may be attributed to variations in the $\mathrm{Al}_{2} \mathrm{O}_{3}$ content as well as the incorporation of additional components in the system, Table III. Therefore, the challenge in relating data from synthetic slags to data from industrial slags is to account for such compositional variations. These results lead to the conclusion that utilizing multiple linear regression is suitable for determining factors that influence $k^{\prime}$, their relative importance, and if they are statistically significant. The developed model can be used to predict changes in industrial slags if these changes represent the major slag constituents. However, the approach is not suitable to model slags outside the boundaries of the utilized system.

In the literature review, Section I-B, several authors utilized the optical basicity measurement to relate the potassium content in $\mathrm{BF}$ slags to the composition of the slag. Since the potassium content in the BF slag is governed by the kinetics of potassium evaporation rather than the content at thermodynamic equilibrium, the relation between optical basicity and potassium content in the slag may be translated to a relation between the optical basicity and apparent rate constant. Therefore, the experiments reported in the present paper were evaluated using the optical basicity, which is calculated according to Eqs. [11] and [12]. More specifically, the corrected optical basicity $\left(\Lambda_{\text {corr }}\right)$ was utilized in order to account for the cationic charge compensation required to incorporate the $\mathrm{Al}^{3+}$ ions into the $\mathrm{SiO}_{4}{ }^{4-}$-tetrahedron network. The charge balancing was performed by deducting the $\mathrm{Al}_{2} \mathrm{O}_{3}$ concentration from the $\mathrm{CaO}$ concentration in Eq. [12]. The latter computation has been described by Mills and Sridhar; ${ }^{[49]}$ in their paper the $\mathrm{Al}_{2} \mathrm{O}_{3}$ concentration was deducted from the concentration of the most basic cation.

$$
\Lambda=\sum_{i=1}^{n} \Lambda_{i} N_{i}
$$

$$
N_{i}=\frac{x_{i} n_{\mathrm{Oi}}}{\sum_{i=1}^{n} x_{\mathrm{i}} n_{\mathrm{Oi}}},
$$

where $\Lambda$ is the optical basicity of the slag, $\Lambda_{i}$ the optical basicity value for component $i, N_{i}$ the equivalent fraction of oxide $i$ in the slag, $x_{i}$ the mole fraction of component $i$ in the slag, and $n_{\mathrm{Oi}}$ the number of oxygen atoms in oxide $i$. 
Table V. Values of Optical Basicity of Component $i\left(\Lambda_{\mathrm{i}}\right)$ from Nakamura et al. ${ }^{[50]}$

\begin{tabular}{lccc}
\hline Compound & $\Lambda_{\mathrm{i}}$ & Compound & $\Lambda_{\mathrm{i}}$ \\
\hline $\mathrm{K}_{2} \mathrm{O}$ & 1.16 & $\mathrm{MgO}$ & 0.92 \\
$\mathrm{Na} 2$ & 1.11 & $\mathrm{Al}_{2} \mathrm{O}$ & 0.66 \\
$\mathrm{BaO}$ & 1.08 & $\mathrm{TiO}_{2}$ & 0.65 \\
$\mathrm{CaO}$ & 1.00 & $\mathrm{SiO}_{2}$ & 0.47 \\
$\mathrm{MnO}$ & 0.95 & $\mathrm{P}_{2} \mathrm{O}_{5}$ & 0.38 \\
$\mathrm{FeO}$ & 0.94 & & \\
\hline
\end{tabular}

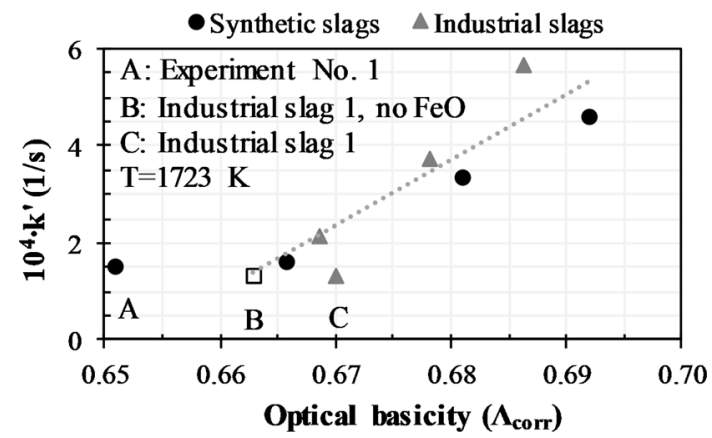

Fig. 9-Apparent rate constant vs corrected optical basicity at 1723 $\mathrm{K}$. White box (point B) denotes industrial slag 1 without FeO.

The optical basicity scale is based on the chosen reference state that the optical basicity for $\mathrm{CaO}\left(\Lambda_{\mathrm{CaO}}\right)$ is unity. The relative values to $\Lambda_{\mathrm{CaO}}$, deduced for other oxide components, have been calculated based on, e.g., Pauling electronegativity ${ }^{[44]}$ or average electron densities. ${ }^{[50]}$ Yang et al. ${ }^{[37]}$ discussed that the values of $\Lambda_{\mathrm{i}}$ presented by Nakamura et al. ${ }^{[50]}$ were more accurate for transition metals as compared to the values presented by Duffy et al. ${ }^{[44]}$ Therefore, the optical basicities of the slags in the present study were calculated based on the values presented by Nakamura et al., ${ }^{[50]}$ Table V.

The results of the calculations are presented in Figure 9, and the corrected optical basicity correlates strongly to the apparent rate constant. Apart from experiment No. 1 (point A in Figure 9), performed on synthetic BF slag, the linear relation between the apparent rate constant and corrected optical basicity had a coefficient of determination of 0.87 . The apparent rate constant of industrial slag 1 deviated slightly from the linear trend of the industrial slags (point $\mathrm{C}$ in Figure 9). However, assuming that the iron oxide content, Table III, was reduced in the experimental conditions, the corrected optical basicity shifted to the left (point B in Figure 9). Based on these results, the corrected optical basicity, excluding $\mathrm{FeO}$, may provide a base for extrapolating the evaporation rate from a particular slag system to a system with additional components. In order to increase the data points for the comparison between the corrected optical basicity and apparent rate constant, previously reported results from the literature were analyzed.
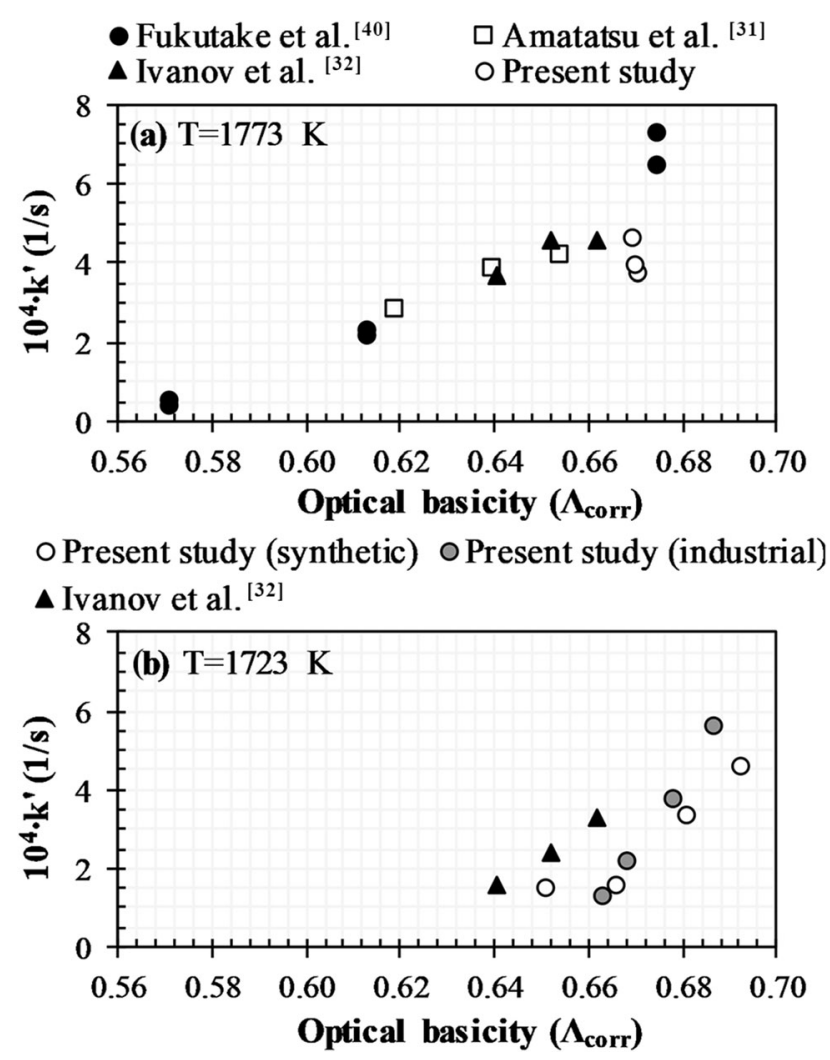

Fig. 10-Apparent reaction rate $v s$ optical basicity at (a) $1773 \mathrm{~K}$ and (b) $1723 \mathrm{~K}$

\section{Comparison to Literature}

Forsberg $^{[43]}$ stated that six factors have the main influence on the mass transfer of potassium from the BF slag to the gas phase: (i) the concentration of potassium in the slag and gas, (ii) the temperature, (iii) the composition of the slag, (iv) the interfacial area between slag and gas, (v) the composition of the gas, and (vi) the flow rate of slag and gas. Furthermore, the prerequisites for describing the potassium evaporation from the slag using the first-order reaction were stated as factors two through six should be constant during the experiment. ${ }^{[43]}$

Considering the second factor, the most frequently used temperature in previously reported experiments is $1773 \mathrm{~K} \cdot{ }^{[31,32,40-43]}$ Out of these studies, the information provided by Friedrichs et al. ${ }^{[41]}$ Shimoo et al. ${ }^{[42]}$ and Forsberg $^{[43]}$ was insufficient to calculate the optical basicity of the slags, i.e., the third aforementioned factor. In terms of the fourth factor, the inner diameter of the crucible utilized by Fukutake et al. ${ }^{[40]}$ Amatatsu et al., ${ }^{[31]}$ and Ivanov et al. ${ }^{[32]}$ were 18,17 , and $15 \mathrm{~mm}$, respectively. Furthermore, regarding the fifth factor, these three studies employed an atmosphere with low oxygen partial pressure. Based on the results presented in the literature review, Section $\mathrm{I}-\mathrm{B}$, the flow rate of the gas can be neglected, i.e., the sixth factor. These aforementioned similarities between the studies by 
Fukutake et al.,${ }^{[40]}$ Amatatsu et al. ${ }^{[31]}$ and Ivanov et al. ${ }^{[32]}$ explain why the results are within the same range, as shown in Figure 10(a).

Interestingly, the results of the triplicate experiment from the present study show similar results as the values from the literature, Figure 10(a), although the inner diameter of the utilized crucible was $70 \mathrm{~mm}$. Possibly, the addition of the graphite cylinders utilized in the experiments of the present study decreased the interfacial area of the slag-gas interface to a comparable area of the previous studies. The experiments performed at $1723 \mathrm{~K}$ are compared to experiments presented by Ivanov et al. ${ }^{[32]}$ at the same temperature, Figure 10(b). Again, the results of the present study are within the same range as previously reported experiments. However, Figure 10(b) indicates differences between the slopes of the relation between the optical basicity and apparent rate constant, which may be attributed to differences between the six aforementioned factors.

Based on the experiments presented in Figure 10, the linear relation between the apparent rate constant and optical basicity was confirmed. Therefore, the optical basicity was concluded to be a possible tool for predicting the evaporation rate of potassium from $\mathrm{BF}$ slags with compositions outside the original dataset.

Considering the results from the equilibrium experiments presented by Kärsrud ${ }^{[33]}$ and evaluated by Berg$\operatorname{man}^{[34]}$ utilizing the optical basicity, there exists a relation between the equilibrium potassium content of BF slag and the optical basicity. Therefore, the driving force to reach a certain potassium content in the BF slag can be described based on the optical basicity. However, since the process is kinetically controlled, the previously observed relation between the optical basicity and final potassium content in the BF slag, as mentioned in Section I-B, is governed by the correlation between the optical basicity and the evaporation rate of potassium.

In order to understand the influence of optical basicity on the apparent rate constant, the diffusion mechanism in silicate melts was considered.

\section{E. The Corrected Optical Basicity and the Apparent Rate Constant}

The overall reaction for the evaporation of potassium from $\mathrm{BF}$ slag is characterized as a heterogeneous reaction system. Therefore, the reaction can be divided into three steps: (i) the mass transfer to the reaction interface, (ii) the reduction and evaporation at the reaction interface, and (iii) the mass transfer through the boundary layer in the gas phase. ${ }^{[51]}$ Considering that both Fukutake et al. ${ }^{[40]}$ and Forsberg ${ }^{[43]}$ found that the flow rate of gas on the slag surface had negligible effects on the apparent rate constant, the third step may be neglected. Furthermore, based on the high temperatures in the lower part of the BF, the reaction rate is less likely to be rate-limiting. ${ }^{[43]}$ Therefore, the mass transfer within the slag phase can be assumed to be the rate-limiting step, which was concluded by Forsberg ${ }^{[43]}$ as well. The relevant parameter to consider is, therefore, the diffusion of potassium in the slag.
In their review of ionic diffusion in glasses, Terai and Hayami ${ }^{[52]}$ summarized that the Stokes-Einstein equation, traditionally used for the diffusion of dilute solutes in liquids, is not suitable for ionic melts such as glasses or metallurgical slags. Instead, the Eyring equation, Eq. [13], provided a reliable description of the diffusion. ${ }^{[52]}$

$$
D=k T / \lambda \eta
$$

where $D$ is the diffusion coefficient $\left[\mathrm{m}^{2} \mathrm{~s}^{-1}\right], k$ is the Boltzmann constant $\left[\mathrm{JK}^{-1}\right], T$ is the temperature $[\mathrm{K}]$, $\lambda$ is the jumping distance [m] (i.e., the mean translation distance for the diffusion jump of the diffusive species regarded as an isometric sphere), and $\eta$ is the viscosity [Pa s].

Based on Eq. [13], the variations in the diffusion of potassium in BF slag can be understood in relation to the variables of the equation. The effect of temperature will not be further discussed as Arrhenius behavior of $k^{\prime}$ has been reported in previous publications. ${ }^{[41-43]}$ The two remaining parameters, jumping distance, and viscosity, are discussed in the text below with regard to optical basicity.

The values of the jumping distance have been determined by comparing the experimental diffusivity data for oxygen in silicate melts to the experimental viscosity data for the same melt composition. ${ }^{[53-55]}$ Oishi et al..$^{[53]}$ found that a jumping distance in the size of the $\mathrm{O}^{2-}$ anion resulted in good agreement between observed diffusivities and values calculated from Eq. [13]. On the other hand, Dunn ${ }^{[54]}$ found the jumping distance in the Eyring equation required larger values to be fitted to his experimental diffusivity data. The jumping distance utilized to fit the experimental data corresponded to the size of the $\mathrm{SiO}_{4}{ }^{4-}$-tetrahedron. ${ }^{[54]}$ Furthermore, Behrens and Haack ${ }^{[55]}$ also identified that the jumping distance was in the size range of the $\mathrm{SiO}_{4}{ }^{4-}$-tetrahedron. In conclusion, the degree of polymerization of the silicate melt, i.e., the slag phase, may determine the jumping distance that describes the diffusion. The diffusion in a more polymerized slag will be associated with larger jumping distances, which decreases the diffusivity. Therefore, as the optical basicity of the slag is a possible measurement to describe the polymerization of the slag, ${ }^{[51]}$ the optical basicity relates closely to the jumping distance, and, therefore, the diffusivity.

The second parameter, i.e., the viscosity, depends on the structural parameters of the slag, such as the degree of polymerization of the slag as well as cation effects, including charge compensation and differences in cation sizes. ${ }^{[56]}$ Mills and Sridhar ${ }^{[49]}$ modeled the structural dependency of slags to the viscosity by utilizing the corrected optical basicity. Further development of the correlation between the viscosity and optical basicity was introduced by Ray and Pal. ${ }^{[57]}$ The empirical equations derived in both papers, relating the viscosity to the optical basicity, showed a clear trend of decreasing viscosities with increasing optical basicities. ${ }^{[49,57]} \mathrm{A}$ direct effect of this demonstrated correlation is the effect 
of the optical basicity on the diffusivity, which relates to the reciprocal relation between the diffusivity and viscosity, Eq. [13].

In light of the above, the suitability of utilizing the optical basicity to describe the evaporation kinetics of potassium from BF slag relates to two factors. First of all, the diffusion of potassium in the slag is the rate-limiting step. Second, the diffusion of potassium is closely related to the properties dependent on the structure of the slag, which can be described by the optical basicity.

\section{CONCLUSIONS}

The present paper addresses the identified characteristics of existing data related to the kinetics of evaporation of potassium from BF slag. A full-factorial design of experiments was utilized to quantitatively study changes in the evaporation rate of potassium (expressed as the apparent rate constant) related to changes in $\mathrm{MgO}$ content, B2 basicity, and temperature concluding that:

1. Alterations in the $\mathrm{MgO}$ content of the slag have a statistically significant positive (i.e., increasing) effect on the apparent rate constant, determined for the 95 pct confidence interval.

2. Multiple linear regression can be utilized to quantitatively describe changes in the apparent rate constant based on changes in the composition and temperature of a synthetic slag within the boundaries of the regression model.

3. Multiple linear regression can be used to predict the apparent rate constant for industrial slags of similar compositions as the synthetic slags but is limited to the boundaries of the model posed by the compositions of the synthetic slags.

The results of the present study, as well as previously reported experiments, were evaluated using the corrected optical basicity, concluding that:

1. There is a linear correlation between the corrected optical basicity and the apparent rate constant describing the evaporation of potassium.

2. The corrected optical basicity offers a possibility to quantitatively relate compositional changes outside the system of synthetic BF slags to the apparent rate constant.

3. The suitability of utilizing the corrected optical basicity in the evaluation relates to the diffusion of potassium in the slag being the rate-limiting step of the overall evaporation reaction and the fact that optical basicity relates closely to the diffusivity of ions in silicate melts.

\section{ACKNOWLEDGMENTS}

The authors thank the European Commission - Research Fund for Coal and Steel for funding this project
"Assessing and control of alkaline circulation in BF operation." The project was conducted within Center for Advanced Mining and Metallurgy (CAMM) at Luleå University of Technology. The assistance provided by Britt-Louise Holmqvist is gratefully acknowledged.

\section{OPEN ACCESS}

This article is licensed under a Creative Commons Attribution 4.0 International License, which permits use, sharing, adaptation, distribution and reproduction in any medium or format, as long as you give appropriate credit to the original author(s) and the source, provide a link to the Creative Commons licence, and indicate if changes were made. The images or other third party material in this article are included in the article's Creative Commons licence, unless indicated otherwise in a credit line to the material. If material is not included in the article's Creative Commons licence and your intended use is not permitted by statutory regulation or exceeds the permitted use, you will need to obtain permission directly from the copyright holder. To view a copy of this licence, visit http://creativec ommons.org/licenses/by/4.0/.

\section{FUNDING}

Open access funding provided by Lulea University of Technology.

\section{REFERENCES}

1. N.N. Chernov, T.V. Demidenko, B.F. Marder, I.E. Pochekailo, and V.V. Taranovskii: Metallurgist, 1983, vol. 27, pp. 153-56.

2. V.P. Gridasov, G.N. Logachev, S.N. Pishnograev, A.V. Pavlov, V.A. Gostenin, and A.V. Chevychelov: Metallurgist, 2016, vol. 59, pp. 761-65.

3. R. Sakurovs, D. French, and M. Grigore: Int. J. Coal Geol., 2007, vol. 72 , pp. 81-88.

4. J.M. Steiler, R. Nicolle, B. Metz, M. Wanin, C. Thirion, and D. Flamion: In Proceedings of the 43rd Ironmaking Conference, Iron and Steel Society of AIME, Chicago, IL, 1984, pp. 427-37.

5. M. Geerdes, R. Chaigneau, I. Kurunov, O. Lingiardi, and J. Ricketts: Modern Blast Furnace Ironmaking: An Introduction, 3rd ed., IOS Press, Delft, The Netherlands, 2015, pp. 169-170.

6. K.X. Jiao, J.L. Zhang, Z.J. Liu, C.L. Chen, and F. Liu: Ironmak. Steelmak., 2017, vol. 44, pp. 344-50.

7. A.A. Polinov, A.V. Pavlov, S.N. Pishnograev, G.N. Logachev, and N.A. Spirin: Metallurgist, 2017, vol. 61, pp. 193-97.

8. D.N. Togobitskaya, N.A. Tsyupa, P.I. Otorvin, and A.S. Skachko: Steel Transl., 2018, vol. 48, pp. 301-06.

9. J. Davies, J.T. Moon, and F.B. Traice: Ironmak. Steelmak., 1978, vol. 4 , pp. 151-61.

10. R.J. Holmes and L. Lu (ed.): Iron Ore: Mineralogy, Processing and Environmental Sustainability, Woodhead Publishing, Elsevier, Cambridge, UK, 2015, p. 39

11. X. Fan, J. Zhang, K. Jiao, J. Zhang, and K. Wang: Can. Metall. Q., 2019, vol. 58, pp. 400-09.

12. S. Chen, W. Wang, R. Xu, S. Deng, and H. Zheng: Ironmaking Steelmaking, 2020, vol. 47, pp. 219-27.

13. D. Senk, H.W. Gudenau, S. Geimer, and E. Gorbunova: ISIJ Int., 2006, vol. 46, pp. 1745-51.

14. A. Wedholm: in Proceeding of SCANMET V, Swerea MEFOS, Luleå, Sweden, 2016, pp. 1-10. 
15. A. Andersson, A. Gullberg, A. Kullerstedt, A. Wedholm, J. Wikström, H. Ahmed, and L. Sundqvist Ökvist: in ISIJ Int., 2019, vol. 59, pp. 1786-95.

16. A. Kemppainen, M. Iljana, E.P. Heikkinen, T. Paananen, O. Mattila, and T. Fabritius: ISIJ Int., 2014, vol. 54, pp. 1539-45.

17. M. Hatano, T. Miyazaki, and Y. Iwanaga: Trans. Iron Steel Inst. Jpn., 1980, vol. 20, pp. 744-52.

18. S. Taguchi, T. Koitabashi, N. Tsuchiya, and H. Takahashi: Tetsu-to-Hagane, 1982, vol. 68, pp. 2346-53.

19. I.F. Kurunov, V.N. Titov, V.L. Emel'yanov, S.A. Lysenko, and A.N. Arzamastsev: Metallurgist, 2009, vol. 53, pp. 533-42.

20. A.A. El-Geassy, K.A. Shehata, M.I. Nasr, and S.S. Fakhoury: Trans. Iron Steel Inst. Jpn., 1986, vol. 26, pp. 865-74.

21. W.J. Rankin and J.B. See: Miner. Sci. Eng., 1977, vol. 9, pp. 68 82.

22. J.D. Ashton, C.V. Gladysz, J.E.R. Holditch, and G.H. Walker: JOM, 1974, vol. 26, pp. 47-54.

23. M. Iljana, O. Mattila, T. Alatarvas, J. Kurikkala, T. Paananen, and T. Fabritius: ISIJ Int., 2013, vol. 53, pp. 419-26.

24. M. Bahgat, K.S. Abdel Halim, H.A. El-Kelesh, and M.I. Nasr: Ironmak. Steelmak., 2009, vol. 36, pp. 379-87.

25. K. Narita, T. Onoye, Y. Satoh, M. Miyamoto, K. Taniguchi, S. Kamatani, T. Sato, and S. Fukihara: Trans. Iron Steel Inst. Jpn., 1981, vol. 21, pp. 839-45.

26. X. Chen, Y. Li, Y. Li, S. Sang, L. Zhao, S. Li, S. Jin, and S. Ge: Metall. Mater. Trans. B, 2010, vol. 41B, pp. 420-29.

27. K.X. Jiao, J.L. Zhang, Z.J. Liu, C.L. Chen, and Y.X. Liu: ISIJ Int., 2016, vol. 56, pp. 1956-63.

28. A. Formoso, F.A. López, J.L.G. Fierro, M.T. Larrea, and A. Cores: Ironmak. Steelmak., 1997, vol. 24, pp. 288-92.

29. N.A. Gladkov, S.A. Nikolaev, and L.G. Budnik: Metallurgist, 1986, vol. 30, pp. 44-46.

30. O. Ivanov, L. Savov, and D. Janke: Steel Res. Int., 2004, vol. 75, pp. $433-41$.

31. M. Amatatsu, V. Stuts, and H.W. Gudenau: Trans. Iron Steel Inst. Jpn., 1985, vol. 25, pp. 949-52.

32. O. Ivanov, L. Savov, and D. Janke: Steel Res. Int., 2004, vol. 75, pp. $442-48$.

33. K. Kärsrud: Scand. J. Metall., 1984, vol. 13, pp. 98-106.

34. A. Bergman: Steel Res., 1989, vol. 60, pp. 383-86.

35. Y.D. Yang, A. McLean, I.D. Sommerville, and J.J. Poveromo: Iron Steelmak., 2000, vol. 27, pp. 103-11.

36. A. McLean, Y.D. Yang, I.D. Sommerville, Y. Uchida, and M. Iwase: High Temp. Mater. Processes, 2001, vol. 20, pp. 185-93.

37. Y.D. Yang, I.D. Sommerville, and A. McLean: Trans. Indian Inst. Met., 2006, vol. 59, pp. 655-69.

38. X. Xing, W. Liu, J. Ju, Z. Pang, and C. Tang: Ironmak. Steelmak., 2019, pp. 1-5.
39. C. Lan, Q. Lyu, X. Liu, M. Jiang, S. Zhang, and F. Li: Trans. Indian Inst. Met., 2018, vol. 71, pp. 2243-49.

40. T. Fukutake, Y. Takada, N. Tsuchiya, and K. Okaba: in Proceedings of Australia/Japan Extractive Metallurgy Symposium 1980, Sydney, Australia, pp. 269-80.

41. H.A. Friedrichs, H.W. Gudenau, and V. Stutz: Arch. Eisenhüttenwes., 1984, vol. 55, pp. 137-42.

42. T. Shimoo, S. Ando, and H. Kimura: J. Jpn. Inst. Met., 1985, vol. 49, pp. 357-63.

43. S. Forsberg: Volatilization of Potassium from Synthetic Slags of Blast Furnace Type, Department of Theoretical Metallurgy, Royal Institute of Technology, Stockholm, Sweden, 1987.

44. J.A. Duffy, M.D. Ingram, and I.D. Sommerville: J. Chem. Soc. Faraday Trans. 1, 1978, vol. 74, pp. 1410-19.

45. W. Altpeter, E. Beppler, B. Gerstenberg, and M. Kannappel: Stahl Eisen, 1988, vol. 108, pp. 781-90.

46. M. Geerdes, G. Cegna, P. Contreras, C. González, F. Liceaga, O. Lingiardi, and H. Toxopeus: in 6th International Congress on the Science and Technology of Ironmaking, Brazilian Association of Metallurgy, Materials and Mining, Rio de Janeiro, Brazil, 2012, pp. 788-97.

47. R. Altland, B. Beckmann, and K.P. Stricker: Stahl Eisen, 1999, vol. 119 , pp. 53-60.

48. L. Eriksson, E. Johansson, N. Kettaneh-Wold, C. Wikström, and S. Wold: Design of Experiments: Principles and Applications, 3rd ed., MKS Umetrics AB, Umeå, Sweden, 2008, pp. 78, 423.

49. K.C. Mills and S. Sridhar: Ironmak.. Steelmak., 1999, vol. 26, pp. 262-68.

50. T. Nakamura, Y. Ueda, and J.M. Toguri: J. Jpn. Inst. Met., 1986, vol. 50 , pp. $456-61$.

51. S. Seetharaman (editor-in-chief), A. McLean, R. Guthrie, and S. Sridhar (co-editors-in-chief): Treatise on Process Metallurgy, Volume 1: Process Fundamentals, Elsevier, Oxford, UK, 2013, pp. 157, 822 .

52. R. Terai and R. Hayami: J. Non-Cryst. Solids, 1975, vol. 18, pp. 217-64.

53. Y. Oishi, R. Terai, and H. Ueda: Mater. Sci. Res., 1975, vol. 9, pp. 297-310.

54. T. Dunn: Geochim. Cosmochim. Acta, 1982, vol. 46, pp. 2293-99.

55. H. Behrens and M. Haack: J. Non-Cryst. Solids, 2007, vol. 353, pp. $4743-52$.

56. M. Sajid, C. Bai, M. Aamir, Z. You, Z. Yan, and X. Lv: ISIJ Int., 2019, vol. 59, pp. 1153-66.

57. H.S. Ray and S. Pal: Ironmak. Steelmak.., 2004, vol. 31, pp. 12530 .

Publisher's Note Springer Nature remains neutral with regard to jurisdictional claims in published maps and institutional affiliations. 